\title{
Exploring the Impact of Heuristic Attributes of Electronic Word of Mouth on Accommodation Sharing Platforms
}

\author{
Yuwan Wang ${ }^{(\bowtie)}$, Lin Li, and Sung-Byung Yang \\ School of Management, Kyung Hee University, 26 Kyungheedae-ro, \\ Dongdaemun-gu, Seoul 02447, South Korea \\ \{w_yuwan, lilin, sbyang\}@khu.ac.kr
}

\begin{abstract}
With the rapid development of the sharing economy, accommodation sharing is a growing trend across the global. Consumers' feelings, opinions, praises, and even criticisms regarding accommodations can be easily posted and shared via review sharing platforms. Word of mouth (WOM) breaks through the oral communication between people, and further turns out to be a more communicative and influential form, electronic word of mouth (eWOM). An empirical approach is applied to explore the relationship between eWOM attributes of accommodation sharing and accommodation popularity on Tujia.com. More specifically, the three heuristic factors of eWOM (i.e., house, review, and host attributes) are identified to influence accommodation popularity, and rental and host types are additionally considered moderating variables to better understand these relationships. This study would provide valuable suggestions for accommodation platform managers and hosts to design more popular accommodations.
\end{abstract}

Keywords: Electronic word of mouth $\cdot$ Accommodation sharing $\cdot$ Heuristic attribute $\cdot$ Accommodation popularity $\cdot$ Tujia.com $\cdot$ Sharing economy

\section{Introduction}

Accommodation Sharing (AS) is one of the fastest growing branches in the sharing economy [1]. The information about houses (rooms) and hosts displayed on AS platforms is easy to get and be used by accommodation seekers. At the same time, users are able to post their reviews freely through these platforms. Thus, the form of word of mouth (WOM) has broken through the oral communication and has become an electronic word of mouth (eWOM) [2]. For experiential products such as hotels and restaurants, eWOM plays an important role in helping make better decision by reducing uncertainty [3]. Previous studies have proven that eWOM has a significant impact on consumers' affirmative intentions [4]. However, research about eWOM in the context of AS has been limited, and the popularity of accommodation has not been paid attention compared to its practical importance. To fill in this gap, the purpose of this study is to explore the influence of different heuristic dimensions of eWOM (i.e., house, review, and host attributes) on accommodation popularity. Moreover, rental (i.e., entire vs. Shared houses) and host (i.e., individual vs. Merchant hosts) types are further 
considered moderating variables to see if those relationships are different according to these types. This research is one of the first attempts to explore the relationship between multi-dimensional heuristic factors of eWOM and accommodation popularity in an AS setting. It would provide hosts and AS platform managers with a depth of knowledge on how accommodation seekers' preferences can be realized through eWOM.

\section{Theoretical Background}

\subsection{Multi-dimensional Heuristic Attributes of eWOM in AS}

eWOM is defined as all informal communications related to specific goods/services by consumers through the Internet [2]. According to [3], when individual's motivation and ability level of information processing are relatively weak or the volume of information to be processed is too large, heuristic processing cues, rather than systematic ones, become dominant. By exploiting multi-dimensional heuristic cues of eWOM (i.e., house, host, and review attributes), users of AS platforms can reduce the cognitive burden when making decisions [5].

\subsection{Accommodation Popularity}

The popularity of accommodation refers to the state of being liked, satisfied, or repurchased by a large number of consumers. There is a significant positive correlation between accommodation popularity and consumers' reservation intention [4]. As prior research used online guest reviews as a performance measure of AS [6], the number of likes is used for measuring accommodation popularity in this study.

\section{Research Model and Hypotheses Development}

Based on literatures on eWOM and the sharing economy including AS, the research model is developed, which is shown in Fig. 1. 


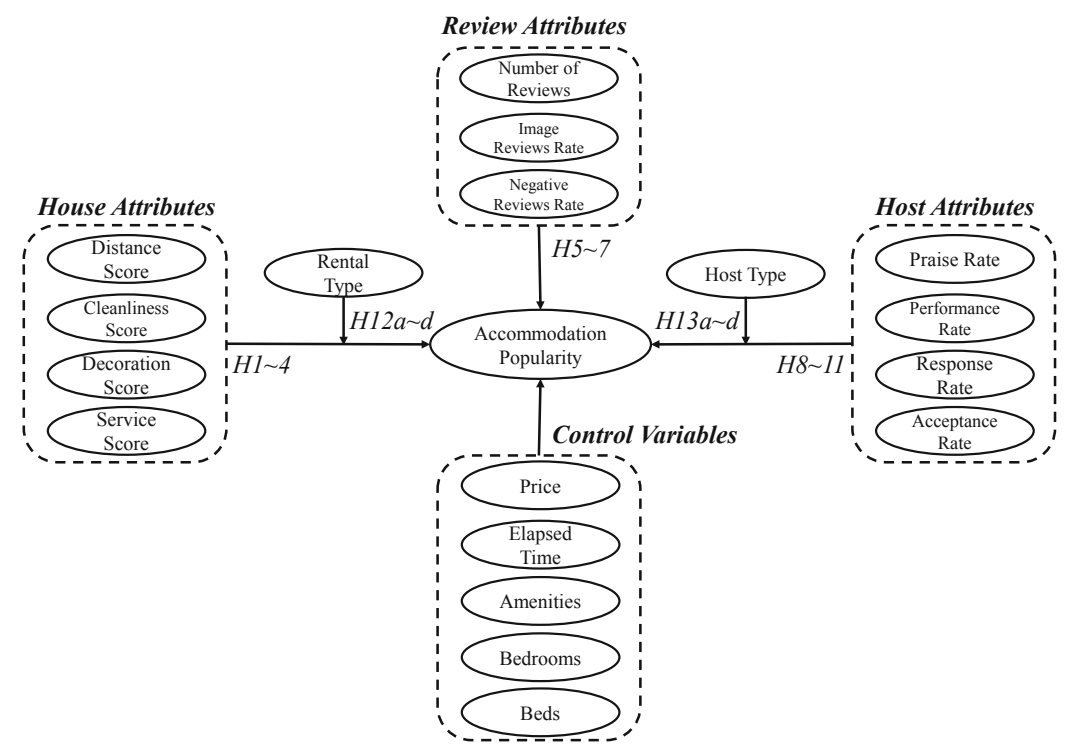

Fig. 1. Research model.

\subsection{House Attributes}

The content analysis of users' perception of AS shows that the main factors are location, landlord, decoration, interactivity, and convenience, with the exception for price $[7,8]$. Similarly, Tujia.com (the target AS platform of the study) offers a review scoring system (1-5 Points) with different key attributes of AS such as location, decoration, service, and cleanliness. As houses (rooms) with high scores are more attractive to (potential) guests, the following hypotheses are proposed:

H1: Distance score has a positive effect on accommodation popularity.

H2: Cleanliness score has a positive effect on accommodation popularity.

H3: Decoration score has a positive effect on accommodation popularity.

H4: Service score has a positive effect on accommodation popularity

\subsection{Review Attributes}

According to extant studies, the number of online user reviews has a positive impact on hotel room sales, vivid and intuitive pictures have a more positive effect on consumers' purchasing decisions than abstract words, and negative reviews are easier to gain consumer trust than positive reviews [9]. Thus, the following hypotheses are posited:

H5: Number of reviews has a positive effect on accommodation popularity.

H6: Image reviews rate has a positive effect on accommodation popularity.

H7: Negative reviews rate has a negative effect on accommodation popularity. 


\subsection{Host Attributes}

Sztompka (1999) [10] proposed three criteria for hosts to gain consumer trust: reputation (past behavior record), performance (actual behavior), and appearance (personal appearance). A high acceptance rate indicates that a host has good service capabilities or abilities to provide enough extra rooms, which helps increase the level of trust to the host and enhances the favorability of the accommodation [4]. The popular accommodation hosts have the characteristics of high rates in terms of praise, performance, response, and acceptance. Thus, the following hypotheses are suggested:

H8: Host's praise rate has a positive effect on accommodation popularity.

H9: Host's performanceH8: Host's praise rate has a positive effect on accommodation popularity.

H10: Host's response rate has a positive effect on accommodation popularity.

H11: Host's acceptance rate has a positive effect on accommodation popularity

\subsection{Moderating Role of Rental Type and Host Type}

The AS occupancy rate can be different according to the rental type as consumers who want to try an entire house put more importance on privacy, while guests who choose to live with a host emphasize the experience of living within the local atmosphere [11]. In the same vein, individual hosts are more popular with consumers who want to live like a local, although merchant hosts can provide more professional services to them. Therefore, the following moderating hypotheses regarding the rental (i.e., entire vs. Shared houses) and host (i.e., individual vs. Merchant hosts) types are proposed:

$H 12 a \sim d:$ The effects of house attributes (distance, cleanliness, decoration, and service scores) on accommodation popularity are different according to the rental type (entire vs. Shared houses).

$H 13 a \sim d:$ The effects of host attributes (praise, performance, response, and acceptance rates) on accommodation popularity are different according to the host type (individual vs. Merchant hosts).

\section{Research Methodology}

This study will employ the data crawling technique to measure variables used in the research model. Accommodations listed on Tujia.com (China's largest AS platform) located in the four tier-one cities in China will be chosen as the target area of data collection. The illustrative sample accommodation on Tujia.com with all variables used in the analysis is presented in Fig. 2. 


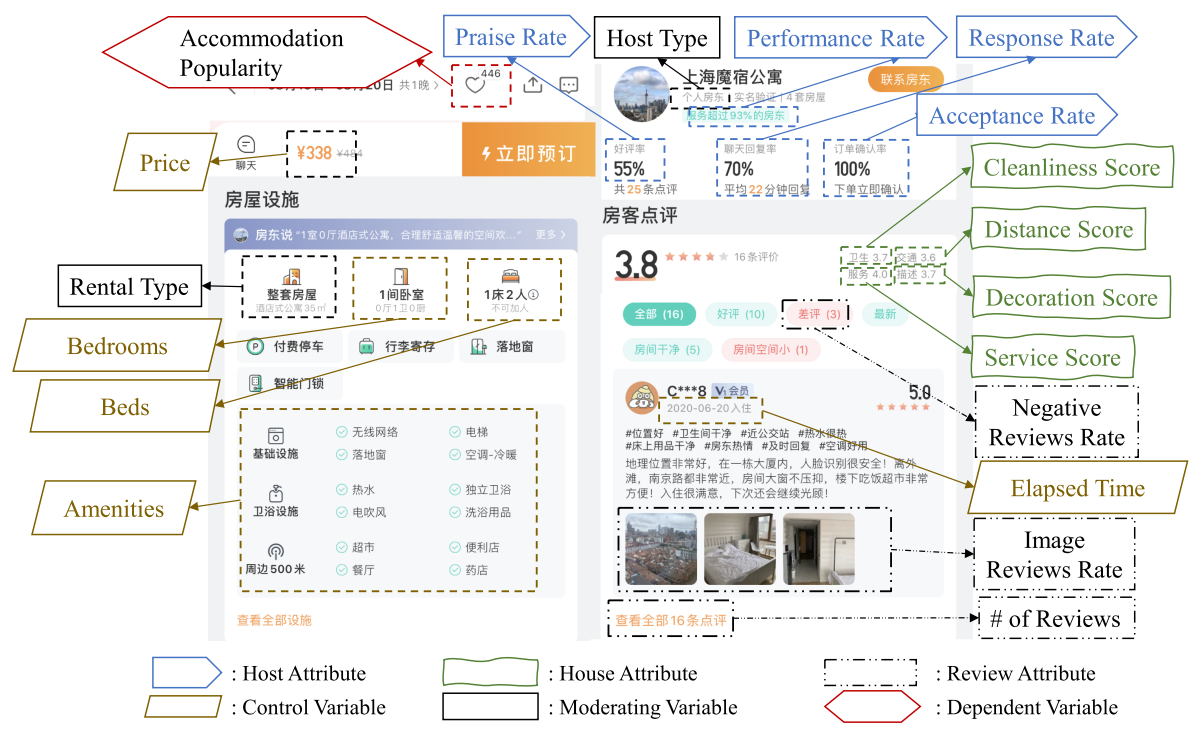

Fig. 2. The illustrative sample accommodation on Tujia.com with all variables measured.

\section{Expected Contributions}

This study is one of the first attempts to explore the relationship between heuristic factors of eWOM and accommodation popularity in the AS context. Moreover, it identifies multi-dimensional heuristic features of eWOM, and examines their impacts on accommodation popularity, expanding the concept of eWOM with a single heuristic dimension into the eWOM with three different heuristic dimensions including house-, review-, and host-related attributes. It would provide valuable insights for AS platform managers and hosts in understanding how accommodation seekers' preferences can be realized through eWOM.

Acknowledgements. This work was supported by the Ministry of Education of the Republic of Korea and the National Research Foundation of Korea (NRF-2019S1A3A2098438).

\section{References}

1. Ganapati S, Reddick CG (2018) Prospects and challenges of sharing economy for the public sector. Gov Inf Q 35(1):77-87

2. Litvin SW, Goldsmith RE, Pan B (2008) Electronic word-of-mouth in hospitality and tourism management. Tourism Manage 29(3):458-468

3. Trumbo CW (2002) Information processing and risk perception: an adaptation of the heuristic-systematic model. J Commun 52(2):367-382

4. Xie KL, Zhang Z, Zhang Z (2014) The business value of online consumer reviews and management response to hotel performance. Int J Hospitality Manage 43:1-2 
5. Liu Z, Park S (2015) What makes a useful online review? Implication for travel product websites. Tourism Manage 47:140-151

6. Liu J, Park J, Xie K, Song H, Chen W (2020) Effect of commercial neighbors on the online popularity of peer-to-peer accommodation-sharing properties. J Hospitality Tourism Res, 1096348020909855

7. Cheng M, Jin X (2019) What do Airbnb users care about? an analysis of online review comments. Int J Hospitality Manage 76:58-70

8. Moon H, Miao L, Hanks L, Line ND (2019) Peer-to-peer interactions: perspectives of Airbnb guests and hosts. Int J Hospitality Manage 7:405-414

9. Ye Q, Law R, Gu B (2009) The impact of online user reviews on hotel room sales. Int J Hospitality Manage 28(1):180-182

10. Sztompka P (1999) Trust: a sociological theory. Cambridge University Press, Cambridge

11. Ma HL, Wong CWH, Leung LC, Chung SH (2020) Facility sharing in business-to-business model: a real case study for container terminal operators in Hong Kong port. Int J Prod Econ 221:107483

Open Access This chapter is licensed under the terms of the Creative Commons Attribution 4.0 International License (http://creativecommons.org/licenses/by/4.0/), which permits use, sharing, adaptation, distribution and reproduction in any medium or format, as long as you give appropriate credit to the original author(s) and the source, provide a link to the Creative Commons license and indicate if changes were made.

The images or other third party material in this chapter are included in the chapter's Creative Commons license, unless indicated otherwise in a credit line to the material. If material is not included in the chapter's Creative Commons license and your intended use is not permitted by statutory regulation or exceeds the permitted use, you will need to obtain permission directly from the copyright holder.

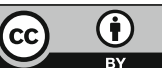

